\title{
Modeling Volatility for Conventional and Islamic Stock Market Indices
}

Farhan Ahmed ${ }^{1}$

Iqra Awais ${ }^{2}$

Dr. Anjum Pervaiz ${ }^{3}$

\begin{abstract}
This study aims to investigate the volatility between Conventional and Islamic stock market by deploying Autoregressive Conditional Heteroskedastic (ARCH) model and Generalized ARCH (GARCH) models along with their variants, Power ARCH (PARCH), Threshold ARCH (TARCH) and Exponential GARCH (EGARCH) on comparable stock market index. Karachi Stock Exchange 30 index (KSE-30) was cross examined with the volatility of KSE Meezan Index (KMI-30) and Dow Jones Islamic Market Index (DJIMI) with Dow Jones Industrial Average (DJIA) to determine the existence of correlation and impact in the volatility of indices. Time effect is being analyzed in the study where the response time to external factors of growing Islamic Market Index is compared to that of a mature Conventional Market Index by applying lags and testifying the ARCH effect on the stationary data, arrived through Augmented Dickey Fuller test, including daily closing prices from 2012 to 2016. The results assess the most appropriate model for each index to be applied for the purpose of forecasting on the basis of volatility. It also established the relationship between comparable index volatility with identifying common denoting factor either the type of the index, that is, Islamic and Conventional or the Geographical Boundaries of the index.
\end{abstract}

Keywords: Stock market indices, Volatility, ARCH

JEL Code: C01, C43, C53

\section{INTRODUCTION}

Financial crisis has impacted investors in making their strategies and designing their portfolio in a way that can help them conquer any adverse movements in the financial markets. Similar strategies were in place earlier where diversification took place within the stocks categories and securities (Miniaoui, Sayani, \& Chaibi, 2015). However stock portfolio and indexes were found to move in similar direction due to correlations that were not identified previously. Hence the search of diversification not only through industry categories were focused upon where alternative assets with high growth became a focal point. In this scenario an average growth of 15 to 20 percent per annum was being realized by the Islamic financial sector over the past decade (IIFM, 2010) that made this sector an interesting opportunity for many investors. For investors, financial institutions and other surplus units in the economy are constantly searching for investment opportunities that have minimum shocks or their volatility and impact can be predicted. Allowing investors to identify the best model of predicting volatility between Islamic and Conventional Index will assist in better strategizing and decision making. The research questions of the study are given as,

1. Is there a relation between the stock indexes composed of conventional and Islamic shares?

\footnotetext{
${ }^{1}$ Department of Management Sciences, Shaheed Zulfikar Ali Bhutto Institute of Science \& Technology, Karachi

2 Standard Chartered Bank Pakistan Limited, Karachi

${ }^{3}$ Sardar Bahadur Khan Women's University, Quetta

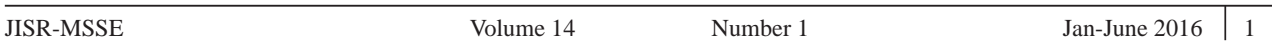


2. With the passage of time are these indexes drifting apart in their patterns and behavior?

3. Is the response time and effect equal in both indexes given local or international shifts in business cycles?

4. Does KMI 30 and DJIMI follow similar patterns with correspondence to the movement in their conventional counterpart indexes?

The limitations of the study includes, time constraints that does not allow other local indexes of other economies to be consider that have established Islamic index and can be compared to the conventional counterparts. There are other international indexes as well which may have greater co-movement with the Islamic Index however may not be opted for. Budget controls does not allow full access of world wide data and use of primary resources to support the study. Furthermore, in next section literature review is discussed in detail with research gaps. After literature review section, research methodology, data analysis and conclusion with recommendations sections are discussed respectively.

\section{LITERATURE REVIEW}

Islamic products makes investment decisions socially responsible with the principles of profit sharing, partnership which is further associated with risk sharing and does not support the concept of fixed returns in the form of interest rates (Girard and Hassan, 2008). The counterpart of conventional investment options the instruments are based on interest where debt based instruments include bonds, debentures, treasury bills and equity based include those that have interest earning as a base for instance shares of banking companies (Merdad, Hassan and Alhenawi, 2010). There are other investment products such as insurance and derivative which have the element of uncertainty in outcomes and speculation. Studying the period from 1996 to 2003 the results showed that when the market is bullish, Islamic indices can perform better but the same cannot be said for bearish market comparing the performance with the conventional counterpart (Hussein, 2005).

All securities in order to come under the umbrella of Shariah compliance requires screening which aims to identify if any core business activity of the said securities are in conflict with the Shariah rules and ideologies. The highlighted points are the interest earnings and expenses as a percentage of total revenue and total expenses, or the aspect of gambling and speculation involved or trading of prohibited goods such as alcohol along with successful completion of Islamic Law of Contracts as per the stated requirements (Rosly, 2005). Due to these restrictions on qualifying a script as Islamic historical research of after financial crisis by Abderrezak (2008) shows a lower Beta maintained by Islamic Equity Funds with poor performance in comparisons to the conventional indices. The study was undertaken on 46 Islamic Equity Funds (IEFs) with the time series data ranging from January 1997 to August 2007. The study apply three factor Fama model having firms with small cap focusing on growth stocks these funds lacked from its potential due to low diversification given a selected number of securities they were able to opt for.

Volatility, as measured by the standard deviation or variance of returns, is often used as a crude measure of the total risk of financial assets (Brooks, 2002), so when referring to international equity markets integration, researchers not only investigate the return causality linkages, but they also measure volatility spillover effects. Information about volatility spillover effects is very useful for the application of value at risk and hedging strategies. The performance of an Islamic index does not fluctuate in the same patterns as the other indexes 
given the unique screening process to make a stock Shariah compliant and the feature within where interest expense or income is not the major component of overall business model (Hakim and Rashidian, 2002). Adding to it the Hussein and Omar (2005) also examined the impact of ethical screening of Islamic indexes to their conventional counterparts. Results showed that Islamic indexes achieve significant abnormal returns to investors over the bullish periods and non-significant risk-adjusted abnormal returns over bearish periods.

Contrasting results were produced by studies finding no significant difference in risk-adjusted returns as compared to the convention stock market index while studying Malaysian Stock Market (Yusof and Majid, 2006) (Albaity and Ahmad, 2006). Similarly Girard and Hassan (2005) and Beik and Wardhana (2009) that no significant difference between Islamic and nonIslamic indices in regards to performance. Testing of volatility done in a study showed that the variance changes in index were similar for conventional and Islamic, not showing any major difference between the two when it comes to the period of financial crisis. However period other than crisis their study concluded that Islamic index tends to be more volatile than the conventional index especially due to the maturity level of the two index and their overall position in the investment market (Charles, Darne and Pop, 2010).

\section{RESEARCH METHODOLOGY}

The impact volatility can have on the stock prices requires the assumption of Homoscedasticity to be overlooked where the variance of error term cannot be constant. To analyze volatility in time series data Robert Engle (1982) introduced Autoregressive Conditional Heteroskedasticity $(\mathrm{ARCH})$. This model has been available to determine volatility clustering by allowing functionality in the variance of error term through stationary data. Bollerslev (1986) extended the model to Generalized ARCH (GARCH) which enables Autoregressive Moving Averages for treating the variance in data. ARCH model incorporates lags and the variance for the variable depends on the previous lags as given in the equation:

$$
\sigma_{t}^{2}=\alpha_{0}+\alpha_{t} u_{t-1}^{2}+\cdots+\alpha_{q} u_{t-q}^{2}
$$

where $\alpha_{0}$ is the positive intercept and $u_{t}$ is a random variable with conditional variance with $q$ lags and squared term.

The analysis for ARCH and GARCH family models require non-linear data with conditions Leptokurtosis, Volatility Clustering and Leverage Effects. Descriptive statistics, histogram and graphs can show the data trend featuring these conditions. OLS (Ordinary Least Square) module will be applied to check the linearity of the four variables separately and the evidence of Heteroscedasticity. Unit Root Test applied for stationary data using Augmented Dickey Fuller (ADF) bringing random walk in the data at first difference. The AIC (Akaike Information Criterion) and SBIC (Schwartz Bayesian Information Criterion) are used to determine the $\mathrm{ARCH}$ model order (the value of q) where the model with the minimum value of information criterion is to be selected.

ARCH equation represents $h_{t}=\sigma_{t}^{2}$ where the functionality is developed as such that the current error terms are a function of sizes of previous error terms. 


$$
h_{t}=\alpha_{0}+\alpha_{1} \varepsilon_{t-1}^{2}+\alpha_{2} \varepsilon_{t-2}^{2} \ldots+\alpha_{q} u_{t-q}^{2}=\alpha_{0}+\sum_{i=1}^{q} \alpha_{i} \varepsilon_{t-i}^{2}
$$

Where $\alpha$ is $\geq 0$ and $i=1, q$ are constant parameters

GARCH allows Autoregressive Moving Average (ARMA) to be part of the ARCH model expressed as:

$$
h_{t}=\alpha_{0}+\sum_{i=1}^{q} \alpha_{i} \varepsilon_{t-i}^{2}+\sum_{i=1}^{p} \beta_{i} h_{t-i}
$$

Where, $\alpha$ and $\beta$ are the parameters, $p$ is the number of lags for past variances and $q$ is the number of lags for past squared residuals.

EGARCH developed by Nelson (1991) introduce asymmetric effect of size on the ARCH/GARCH models by applying logarithmic function to the equation

$$
\operatorname{Ln}\left(h_{t}\right)=\alpha_{0}+\sum_{i=1}^{q} \alpha_{i}\left(\left|\frac{\varepsilon_{t-i}}{\sqrt{h_{t-i}}}\right|-\sqrt{\frac{2}{\pi}}\right)-\sum_{i=1}^{q} \gamma_{i}\left(\frac{\varepsilon_{t-i}}{\sqrt{h_{t-i}}}\right)+\sum_{i=1}^{p} \beta \ln \left(h_{t-i}\right)
$$

Glosten, Jagannathan, and Runkle's (1993) (GJR-GARCH) model assumes that the impact of squared residuals on the variance depends on whether the residual term is negative or positive. For this purpose, it employs an indicator function as follows:

$$
h_{t}=\alpha_{0}+\sum_{i=1}^{p} \beta_{i} h_{t-i}+\sum_{i=1}^{q} \alpha_{i} \varepsilon_{t-i}^{2}+\sum_{i=1}^{q} \gamma_{i} S_{t-i}^{+} \varepsilon_{t-i}^{2}
$$

The indicator function $\mathrm{S}^{+}{ }_{t-i}$ takes a value of 1 if $\varepsilon_{\mathrm{t}-\mathrm{i}} 0$, and 0 otherwise. For the effect of the previous period's bad news to be greater than the effect of good news of the same magnitude, $\gamma$ should be significant and have a negative sign.

TARCH was introduced by Zakoïan's (1994) as:

$$
h_{t}^{1 / 2}=\alpha_{0}+\sum_{i=1}^{p} \beta_{i} h_{t-i}^{1 / 2}+\sum_{i=1}^{q} \alpha_{i} \varepsilon_{t-i}^{+}+\gamma_{i}\left|\varepsilon_{t-i}^{-}\right|
$$

Another version of TARCH applied by Taylor (1986) and Schwert (1989) taking the shock size effect on volatility is

$$
h_{t}^{1 / 2}=\alpha_{0}+\sum_{i=1}^{p} \beta_{i} h_{t-i}^{1 / 2}+\sum_{i=1}^{q} \alpha_{i}\left|\varepsilon_{t-i}\right|
$$

The model shows separate impact of positive and negative changes in volatility. The two variables $\gamma$ and $\alpha$ show bad news and good news as coefficients in the equation.

To find which model is best for each of the four market indices Akaike Information Criterion (AIC) and Schwartz

\begin{tabular}{l|llll}
\hline 4 & Jan-June 2016 & Volume 14 & Number 1
\end{tabular} 
Bayesian Criterion (SBC) is checked by the following equations:

$\mathrm{AIC}(\mathrm{P})=2 \ln ($ maximum likelihood $)-2 \mathrm{P}$

where $\mathrm{P}$ denotes number of parameters.

Some have found that this leads to models chosen with too many parameters, and a second criterion attributed to Schwartz, the Schwartz Bayesian Criterion (SBC), is given by

$\mathrm{SBC}(\mathrm{P})=2 \ln ($ maximum likelihood $)-\mathrm{P} \ln (\mathrm{T})$

where $\mathrm{T}$ is the number of observations

\section{DATA ANALYSIS AND FINDINGS}

Autoregressive Conditional Heteroscedasticity (ARCH) family models have been applied on the four indices of the study. Residual diagnostics were tested for all the indices, DJIA, DJIM, KSE 30 and KMI 30 for all indices, it is analyzed that the probability value of chi square is less than 0.05 resulting in the strong evidence of the ARCH effect. Furthermore, residual graphs have been analyzed for all indices where the all four series are not stationary and do not show the random walk behavior. In continuation of the above discussion, first of all, descriptive statistics are computed.

Descriptive statistics is given below in Table 1 that shows the data of index points with 951 observations is not normally distributed with Probability Value of Jarque Bera less than 0.05. Furthermore the residual graphs in Appendix also indicates that the variables have non stationary data. To apply ARCH and GARCH family models the conditions of Leptokurtosis, Volatility Clustering and Fat Tails have to be fulfilled.

Table 1.

Descriptive Statistics for the indices are given in

\begin{tabular}{lcccrrrrrr}
\hline Index & Mean & Max & Min & Stan Dev. & Skewness & Kurtosis & Jarque Bera & Prob. & Obs. \\
DJIA & 15904.95 & 18312.39 & 12101.46 & 1680.48 & -0.537 & 2.128 & 75.87 & 0.00 & 951 \\
DJIMI & 2710.630 & 3033.600 & 2166.950 & 209.4303 & -0.538 & 2.177 & 72.67 & 0.00 & 951 \\
KSE 30 & 18005.31 & 22614.13 & 11499.50 & 3148.268 & -0.597 & 1.990 & 96.77 & 0.00 & 951 \\
KMI 30 & 42844.75 & 60233.64 & 14911.97 & 11191.53 & -0.349 & 1.823 & 74.11 & 0.00 & 951 \\
\hline
\end{tabular}

This table explains the central tendency and dispersion measures for all four indices undertaken in this study.

Analyzing the descript statistics it shows that the data of index points in with 951 observations is not normally distributed with Probability Value of Jarque Bera less than 0.05 . Furthermore the residual graphs in Appendix also indicates that the variables have non stationary data. To apply ARCH and GARCH family models the conditions of Leptokurtosis, Volatility Clustering and Fat Tails have to be fulfilled.

The data of closing index prices of the four indices are taken on first level of difference to accomplish stationary data with random walk behavior. Table 2 shows Augmented Dickey Fuller test for unit root for level and first difference of the variable in making the data stationary. 
Table 2 .

Augmented Dickey Fuller Unit Root Test

\begin{tabular}{ll}
\hline Series & \multicolumn{1}{c}{ Stationary Results } \\
\hline DJIA & The series is stationary at first difference. I(0) \\
DJIM & The series is stationary at first difference. I(1) \\
KSE 30 & The series is stationary at first difference. I(1) \\
KMI 30 & The series is stationary at first difference. $\mathrm{I}(1)$ \\
\hline This table shows stationarity of the data and ADF test is applied.
\end{tabular}

With the ADF results there is Unit Root at level with zero order of integration for all the indices alike. Null hypothesis fail to reject at $\mathrm{I}(0)$. At first level data has no unit root with Probability values less than 0.05 . Different confidence intervals are taken into consideration and for all indices at the differing values of marginal error the unit root is present at $\mathrm{I}(0)$ and removed at $\mathrm{I}(1)$.

The variables at first difference have stationary data with random walk behavior and volatility clustering as shown in Figure 1 to 8 below.
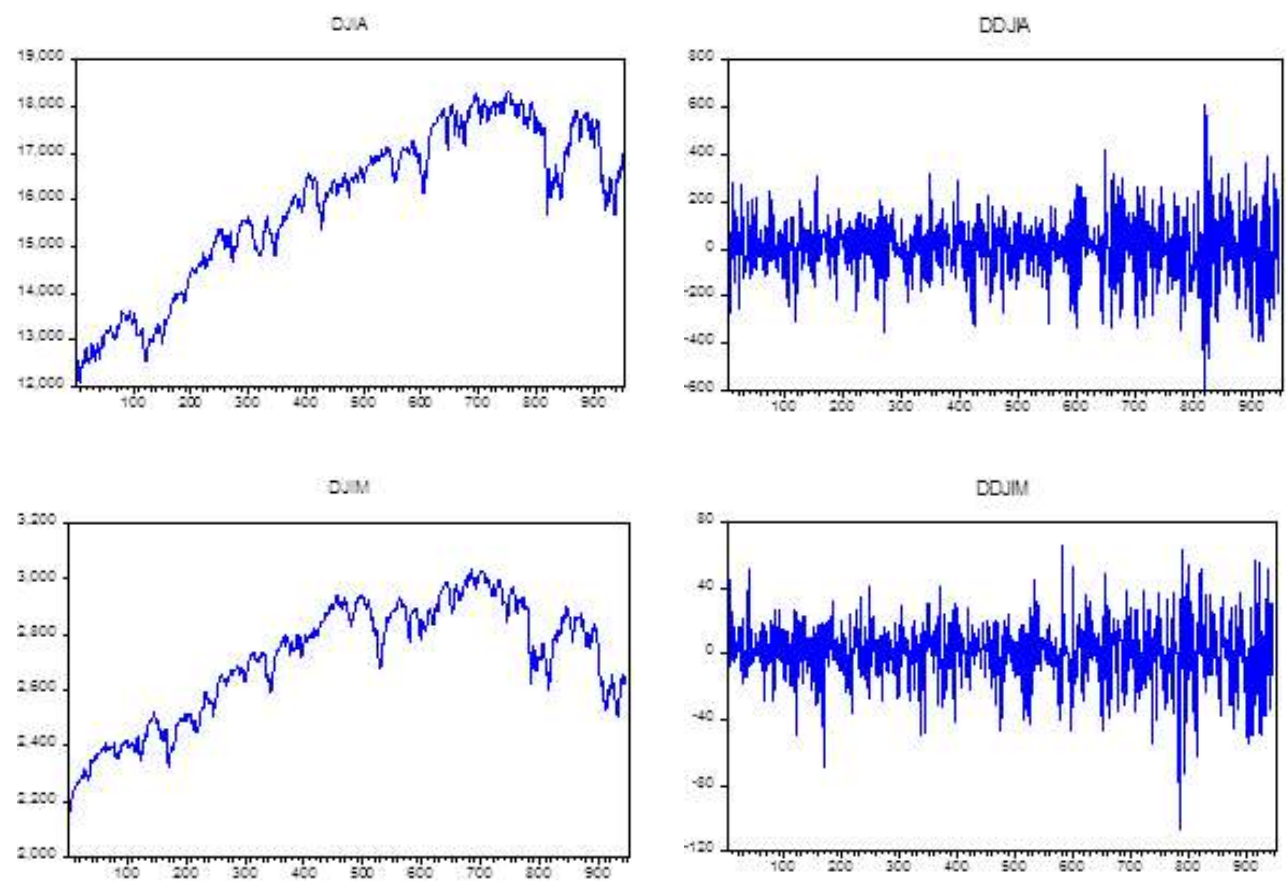

\begin{tabular}{l|llll}
\hline 6 & Jan-June 2016 & Volume 14 & Number 1
\end{tabular} 

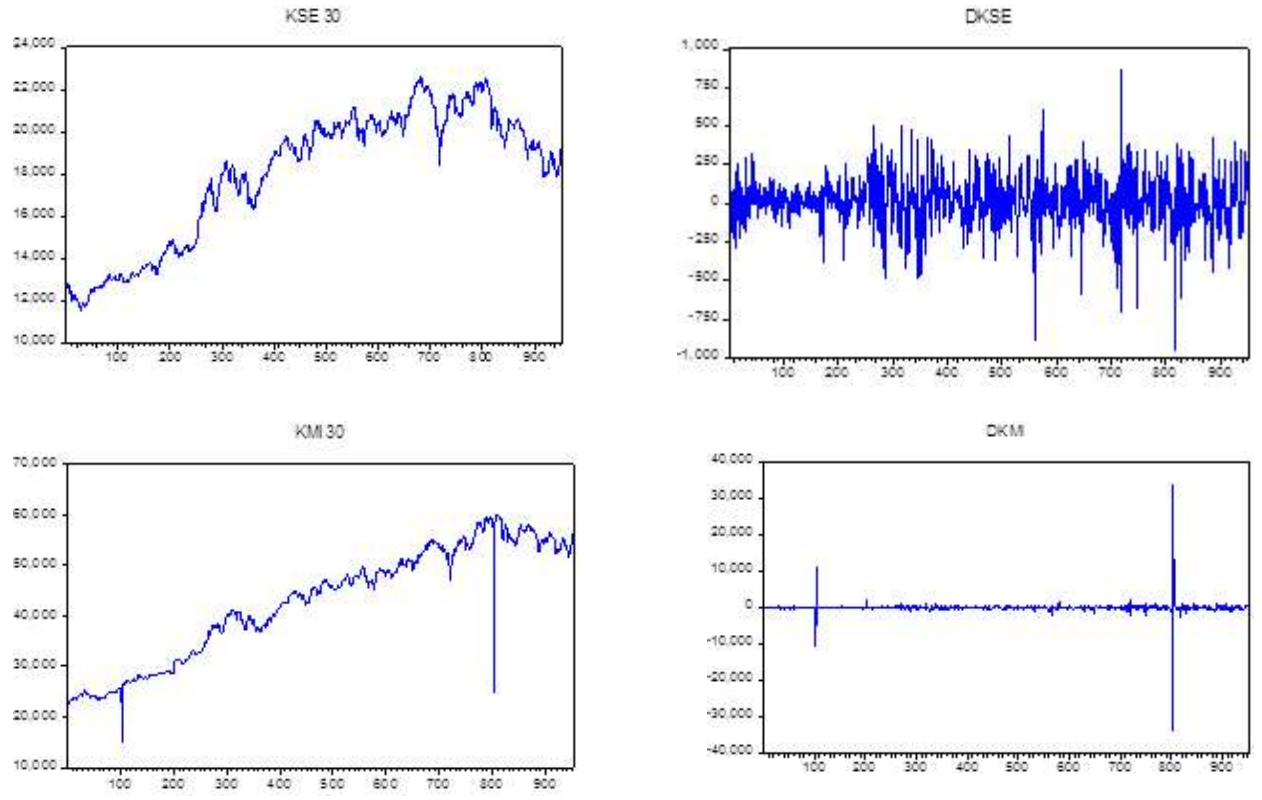

The ARCH and GARCH family models have been applied to the indices at first level of difference with stationary effect. AIC and SIC are two information criterion indicating the best model for each stock index. The results of information criterion are given in table 3 below. For conventional index DJIA the lowest AIC is for PARCH model also known as GJR-GARCH. In accordance with Schwarz Criterion (SIC) the EGARCH model is more appropriate. Hannan-Quinn also suggest PARCH to be a better indicator for volatility estimations. Conventional local index KSE 30 results show that AIC suggests PARCH as best estimator however both SIC and Hannan-Quinn criterion indicate EGARCH as a better model. For Islamic index DJIM on international level suggest EGARCH as the best model with results of all three criterion. KMI 30 was tested and the results suggest AIC, SIC and Hannan-Quinn are all in favor of GARCH model to be applied for volatility estimations. 
Table 3.

Model Selection

\begin{tabular}{lccccc}
\hline $\begin{array}{l}\text { Conventional } \\
\text { DJIA }\end{array}$ & ARCH & GARCH & EGARCH & TARCH & PARCH \\
AIC & & & & & \\
Schwarz Criterion & 12.51289 & 12.40241 & 12.32262 & 12.34108 & 12.31966 \\
Hannan-Quinn & 12.53333 & 12.42797 & 12.35330 & 12.37176 & 12.35544 \\
KSE 30 & 12.52068 & 12.41215 & 12.33431 & 12.35277 & 12.33329 \\
AIC & & & & & \\
Schwarz Criterion & 13.07016 & 12.99511 & 12.94102 & 12.96807 & 12.94039 \\
Hannan-Quinn & 13.09061 & 13.02067 & 12.97170 & 12.99875 & 12.97618 \\
\hline Islamic & 13.07795 & 13.00485 & 12.95271 & 12.97976 & 12.95403 \\
DJIM & & & & & \\
AIC & & & & & \\
Schwarz Criterion & 8.691476 & 8.573963 & 8.464099 & 8.494851 & 8.475047 \\
Hannan-Quinn & 8.711924 & 8.599523 & 8.494771 & 8.525523 & 8.510832 \\
KMI 30 & 8.699267 & 8.583701 & 8.475785 & 8.506537 & 8.488682 \\
AIC & & & & & \\
Schwarz Criterion & 16.97522 & 16.93258 & 17.13079 & 16.93719 & 17.55341 \\
Hannan-Quinn & 16.99567 & 16.95814 & 17.16146 & 16.96786 & 17.58919 \\
\hline $\begin{array}{l}\text { This tables shows the estimated values of all the available information criterion to select the best model for } \\
\text { all four indices undertaken in this study. }\end{array}$ & & & &
\end{tabular}

For conventional index DJIA the lowest AIC is for PARCH model also known as GJRGARCH. In accordance with Schwarz Criterion (SIC) the EGARCH model is more appropriate. Hannan-Quinn also suggest PARCH to be a better indicator for volatility estimations. Conventional local index KSE 30 results show that AIC suggests PARCH as best estimator however both SIC and Hannan-Quinn criterion indicate EGARCH as a better model. For Islamic index DJIM on international level suggest EGARCH as the best model with results of all three criterion. KMI 30 was tested and the results suggest AIC, SIC and HannanQuinn are all in favor of GARCH model to be applied for volatility estimations.

\section{CONCLUSION AND RECOMMENDATIONS}

Index points represents the stock market performance of an economy which in turn represents the economic stability of the particular country. The importance of index points have been established by many economists and the hindrance in performance is subject to the volatility and fluctuations that increases risks for the investors. With respect to the research questions established earlier in the study, the drawn conclusion identifies that Islamic and conventional stock indexes operate at different frequencies of volatility. The screening methodology applied for Islamic Index such as DJIM and KMI 30 restricts their exposure to interest rate risks. However it may also restrict diversification element within the portfolio however the impact of the same is not seen in the index performance. For similar time period a graphical analysis of the index performance shows that the size of fluctuations in Islamic index is comparatively less than the conventional index in both markets.

\begin{tabular}{l|llll}
\hline 8 & Jan-June 2016 & Volume 14 & Number 1
\end{tabular}


The Islamic indices are gradually establishing their own patterns or business cycle but the results are not clear with absolute surety that they are drifting further from the patterns of conventional. The correlation is still significantly high and positive showing direct relation between the index movements. The response time is not the same for conventional and Islamic index neither is the impact of fluctuation especially in the local market comparing KMI 30 with KSE 30 index. KMI 30 has a flatter curve with fewer clustering points different from that of KSE 30. It could also be due to the fact that the KMI 30 index is relatively new in the market with limited stocks and trading activity. Comparing DJIM with DJIA the patterns and impacts are similar.

1

On analyzing all four variables the patterns followed during the period from 2012 to 2016 there is not much variation. The international and local indices have followed similar trends reducing the overall benefits that were provided by international diversification of the portfolio. Grubel (1968) had suggested the theory of Internationally Diversified Portfolio. However it has been in a different era which did not have similar advancement in technology and ease of capital flight. As the different economies integrate overtime the correlations increase and the movements are matched to the financial behavior of global and local investors. The rise and fall in the cycle have some lag but cannot be identified in absolute terms. Moving forward the difference will further reduce between Islamic and Conventional as Islamic stock market reaches maturity levels. Also the international and local movements will merge given the markets approaching strong information databases. For this particular study only four indices were considered for the conclusion that the advantages of diversification in international markets are gradually reducing. However inclusion of more indices from different regions may alter this result.

The study nevertheless show that Islamic and conventional indices have significant differences. With the volatility measurement model PARCH has been more popular in conventional index whereas EGARCH and GARCH has more significance for the Islamic index. Specific to local KMI 30 being on maturity stages and having least amount of clustering the results indicate application of GARCH to provide best results. For further study the sample period can increase from 5 years data to 10 year data giving a better analysis of volatility in conventional and Islamic markets. For this particular study only closing prices has been taken for data analysis. A more in depth analysis can take closing and opening prices along with volumes traded to see the actual impact of volatility from different perspective on the index points. Longitudinal studies can take place on the basis of this study to analyze the changes in model if any needed as suggested by the study for a variety of stock market index points. It is recommended on the basis of results of data analysis that investors strategizing diversification on the basis of Grubel theory of 1968 may have to re think their strategy and conclude if the theory is still applicable for their portfolios or have become obsolete. The international movements and volatility have all taken similar patterns of business cycle with little time lag that can be considered insignificant in the near future. Hedging techniques will be flawed if based on investments of different geographical regions. Islamic and conventional differences are still in place to certain extent where the Islamic financial markets are still in growth phase gradually reaching peak. The volatility analysis is different in terms of model application where GARCH and EGARCH has more significance for Islamic stock market index. Volatility levels of fairly new index is low hence diversification can also take place 
on the basis of index maturity. As seen by trend analysis KMI 30 established in 2008 gives similar returns in percentage term but the level of risk is lower. Same principles can be applied to other indices that are new in the global markets for investors to explore and reduce their risk exposures.

\section{REFERENCES}

Abderrezak, F. (2008). The performance of Islamic equity funds: A comparison to conventional, Islamic and ethical benchmarks. Retrieved April, 1, 2010.

Abdul Karim, B., Akila Mohd. Kassim, N., \& Affendy Arip, M. (2010). The subprime crisis and Islamic stock markets integration. International Journal of Islamic and Middle Eastern Finance and Management, 3(4), 363-371.

Abdul Rahman, A., Azlan Yahya, M., \& Herry Mohd Nasir, M. (2010). Islamic norms for stock screening: A comparison between the Kuala Lumpur stock exchange Islamic index and the dow jones Islamic market index. International Journal of Islamic and Middle Eastern Finance and Management, 3(3), 228-240.

Achsani, N., Effendi, J. A. E. N. A. L., \& Abidin, Z. A. E. N. U. L. (2007). Dynamic interdependence among international Islamic stock market indices: evidence from 2000-2007. In Proceedings of the International Conference of the Islamic Capital Markets, Jakarta, Indonesia.

Albaity, M., \& Ahmad, R. (2008). Performance of Syariah and composite indices: Evidence from Bursa Malaysia. Asian Academy of Management Journal of Accounting and Finance, 4(1), 23-43.

Al-Zoubi, H. A., \& Maghyereh, A. I. (2007). The relative risk performance of Islamic finance: a new guide to less risky investments. International Journal of Theoretical and Applied Finance, 10(02), 235-249.

Arshad, S., \& Rizvi, S. A. R. (2013). The Impact of Global Financial Shocks to Islamic Indices: Speculative Influence or Fundamental Changes? Journal of Islamic Finance, 2(1).

Beik, S. I., and Wardhana, W., (2009)."The Relationship between Jakarta Islamic Index and Other Selected Markets: Evidence from Impulse Response Function" Persatuan Pelajar Indonesia International Islamic University Malaysia.ppiiium.org/.../The\%20Relationship\%20between \%20JII\% 20\&\%20US.pdf.

Bollerslev, T. (1986). Generalized autoregressive conditional heteroskedasticity. Journal of econometrics, 31(3), 307-327.

Charles, A., Pop, A., \& Darné, O. (2011, May). Is the Islamic Finance Model More Resilient than the Conventional Finance Model? Evidence from Sudden Changes in the Volatility of Dow Jones Indexes. In International Conference of the French Finance Association (AFFI).

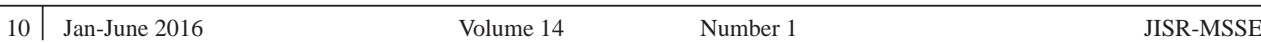


Darrat, A. F., Rahman, S., \& Zhong, M. (2003). Intraday trading volume and return volatility of the DJIA stocks: A note. Journal of Banking \& Finance, 27(10), 2035-2043.

El Qorchi, M. (2005). Islamic finance gears up. Finance and Development, 42(4), 46.

Engle, R. F. (1982). Autoregressive conditional heteroscedasticity with estimates of the variance of United Kingdom inflation. Econometrica: Journal of the Econometric Society, 987-1007.

Girard, E. C., \& Hassan, M. K. (2008). Is there a cost to faith-based investing: Evidence from FTSE Islamic indices. The Journal of Investing, 17(4), 112-121.

Glosten, L. R., Jagannathan, R., \& Runkle, D. E. (1993). On the relation between the expected value and the volatility of the nominal excess return on stocks. The journal of finance, 48(5), 1779-1801.

Grubel, H. G. (1968). Internationally diversified portfolios: welfare gains and capital flows. The American Economic Review, 58(5), 1299-1314.

IIFM, I. (2010). A comprehensive study of the International Sukuk market. Manama: International Islamic Financial Market.

Merdad, H., Hasan, M. K., \& Alhenawi, Y. (2010). Islamic versus conventional mutual funds performance in Saudi Arabia: a case study. Islamic Economics, 23(2).

Miniaoui, H., Sayani, H., \& Chaibi, A. (2015). The impact of financial crisis on Islamic and conventional indices of the GCC countries. Journal of Applied Business Research, 31(2), 357.

Nelson, D. B. (1991). Conditional heteroskedasticity in asset returns: A new approach. Econometrica: Journal of the Econometric Society, 347-370.

Rana, M. E., \& Akhter, W. (2015). Performance of Islamic and conventional stock indices: empirical evidence from an emerging economy. Financial Innovation, 1(1), 1.

Rizvi, S. A. R., Dewandaru, G., Bacha, O. I., \& Masih, M. (2014). An analysis of stock market efficiency: Developed vs Islamic stock markets using MF-DFA. Physica A: Statistical Mechanics and its Applications, 407, 86-99.

Rizvi, S. A. S.(2012)"Are Islamic Equity Indices a Safer Haven in Times of Crisis? An Empirical Proof Via Investigation of Global Indices Using Multivariate GARCH DCC.". In International Islamic Capital Market Conference, Indonesia.

Rosly, S. A. (2005). Islamic banking: doing things right and doing right things. Malaysian Journal of Economic Studies, 42(1/2), 31.

Shabri Abd. Majid, M., Kameel Mydin Meera, A., \& Azmi Omar, M. (2008). Interdependence of ASEAN-5 stock markets from the US and Japan. Global Economic Review, 37(2), 
201-225.

Siddiqui, R. (2006). Shari'ah Compliance, Performance, and Conversion: The Case of the Dow Jones Islamic Market Index. Chi. J. Int'l L., 7, 495.

Xiao, L., \& Dhesi, G. (2010). Volatility spillover and time-varying conditional correlation between the European and US stock markets. Global Economy and Finance Journal, $3(2), 148-164$.

Yang, S. Y. (2005). A DCC analysis of international stock market correlations: the role of Japan on the Asian Four Tigers. Applied Financial Economics Letters, 1(2), 89-93.

Yusof, R. M., \& AbdulMajid, S. (2007). Stock market volatility transmission in Malaysia: Islamic versus conventional stock market. Islamic Economics, 20(2).

Zakoian, J. M. (1994). Threshold heteroskedastic models. Journal of Economic Dynamics and control, 18(5), 931-955. 